\title{
The meteoroid above Mediterranean Sea on July, 6th 2002 was a fragment of a cometary nucleus?
}

\author{
Klim I. Churyumov, ${ }^{1}$ Vitaly G. Kruchynenko, ${ }^{1}$ Larissa S. Chubko ${ }^{2}$, \\ and Tatyana K. Churyumova ${ }^{1}$ \\ ${ }^{1}$ Kyiv Shevchenko National University, \\ Box 04053, Observatorna str., 3, Kyiv, Ukraine \\ email: klim.churyumov@observ.univ.kiev.ua \\ ${ }^{2}$ National Aviation University, \\ Box 03680, Kosmonavta Komarova ave. 1, Kiev, Ukraine
}

\begin{abstract}
It is shown, that the explosion of the bolide above the Mediterranean sea on July, 6th 2002 with a high probability was a fragment of an icy cometary nucleus which initial weight was equal approximately to $7 \cdot 10^{8}$ grams. This follows from the determined energy of the outburst equal to $26 k T$ of TNT (Brown et al. 2002). We think that this energy refers to the height of the maximal braking of the body in the Earth's atmosphere. At the speed of $20.3 \mathrm{~km} / \mathrm{s}$ accepted by authors, the weight of a body at this height is equal $5 \cdot 10^{8} \mathrm{gr}$, and at the entrance in the atmosphere it was approximately of $7 \cdot 10^{8} \mathrm{gr}$.
\end{abstract}

Keywords. meteors, meteoroids, bolide, comet, Earth

\section{Distribution of meteoroids masses in the atmosphere of Earth}

In (Brown et al. 2002) are given the results of the analysis of large meteoroids flashes in the Earth's atmosphere, obtained by USA geostationary satellites. For 8.5 years (from February 1994 to September 2002) 300 such phenomena were registered. On the basis of the data about optical energies of these bolides, and considering velocities at their input into the atmosphere of $20.3 \mathrm{~km} / \mathrm{s}$ and density of $3 \mathrm{~g} / \mathrm{cm}^{3}$, the distribution of diameters of falling bodies is obtained. The considered value of the velocity is close to $21 \mathrm{~km} / \mathrm{s}$, which follows data from catalogues (McCrosky et al. 1976; 1977) for bodies which initial mass is not inferior to $1 \mathrm{~kg}$ (Kruchinenko, 2002). On these basis, the integral distribution of diameters of bodies is given (Brown et al. 2002). This distribution can be transformed in distribution of masses as:

$$
\begin{aligned}
& \log N_{R}=7.146-0.90 \log \mathrm{m} \\
& \log N_{C}=7.86-0.892 \log \mathrm{m}
\end{aligned}
$$

where $N_{R}$ is the flux of bodies with masses not inferior to $m$ (in grams) per one year on the whole Earth. The interval of the masses $6.5 \cdot 10^{5} \mathrm{~g} \ldots 1.0 \cdot 10^{13} \mathrm{~g}$ follows from the interval of observed energies of $3.2 \cdot 10^{-2} k t \ldots 5.0 \cdot 10^{5} k t$. Comparison of dependence (1.1) and the generalized formula, got by (Kruchinenko, 2002), with (2.1) shows that both the curves almost do not differ except by the value of inclination (or by a parameter, characteristic of the distribution of bodies in mass), but there is a considerable shift in the ordinate. We suppose, that this difference can be related to that of the energies of flashes (explosions) which take place deeply in the atmosphere at the heights of the maximal braking of $H_{*}$ and authors consider as that of their entrance in the atmosphere. 
We accept the following first approach: all the bodies of a given interval of mass attained the height of $H_{*}$ and exploded. All the remaining mass of the meteoroids at the height of $H_{*}$ went away in a flash. This possibility only occurs in the case of comet bodies. If speed at the entrance in the atmosphere was $20.3 \mathrm{~km} / \mathrm{s}$, at explosion it will be equal approximately $12 \mathrm{~km} / \mathrm{s}$, and the mass of the body will become equal to $0.78 m_{0}$. Then the corrected interval of initial energies will be: $0.13 \mathrm{kt}$. $-2.0 \cdot 10^{6} \mathrm{kt}$, and the interval of corrected the initial masses: $2.6 \cdot 10^{6} \mathrm{~g} \ldots 4.1 \cdot 10^{13} \mathrm{~g}$. In this case we will get the integral distribution of the flux of bodies in masses as:

$$
\lg N_{R}^{*}=7.685-0.90 \operatorname{lgm}
$$

Comparing equation (1.3) with (1.1) we note that the shift on the ordinate decreased by 4 times and substantially approaches equation (1.2). Among observed phenomena there are those which initial masses exceed $10^{9} \mathrm{~g}$. From the above calculations, we assert that all flashes of meteoroids given in (Brown et al. 2002) corrected the masses of which are in the interval of $10^{9} \mathrm{~g} \ldots 4.1 \cdot 10^{13} \mathrm{~g}$, are caused the comet bodies of low density and that fully split at heights $H_{*}$. In other words, all flashes energies which exceed $20 k t$ are generated by comet bodies. According to this results, in this selection there are not more than two. At least, the bolide registered on July, 62002 (Fig. 1) above Mediterranean Sea and with an estimated energy equal to $26 \mathrm{kt}$, was generated by a cometary body. Accordingly, the density of the body would be of $1 \mathrm{~g} / \mathrm{cm}^{3}$ and having a high initial velocity $(\sim 30 \mathrm{~km} / \mathrm{s})$.

\section{Conclusion}

Thus, we believe that the explosion of the meteoroid above Mediterranean, with high probability, was generated by a cometary body the initial mass of which was equal approximately to $7 \cdot 10^{8} \mathrm{~g}$. This follows from the energy of the flash, equal to $26 \mathrm{kt}$ TNT (Brown et al. 2002). We consider that this energy belongs to the height of the maximal breaking. At the velocity of $20.3 \mathrm{~km} / \mathrm{s}$, accepted by the authors, the mass of body at this height was equal to $5 \cdot 10^{8} \mathrm{~g}$ and of approximately $7 \cdot 10^{8} \mathrm{~g}$ at its entrance into the atmosphere.

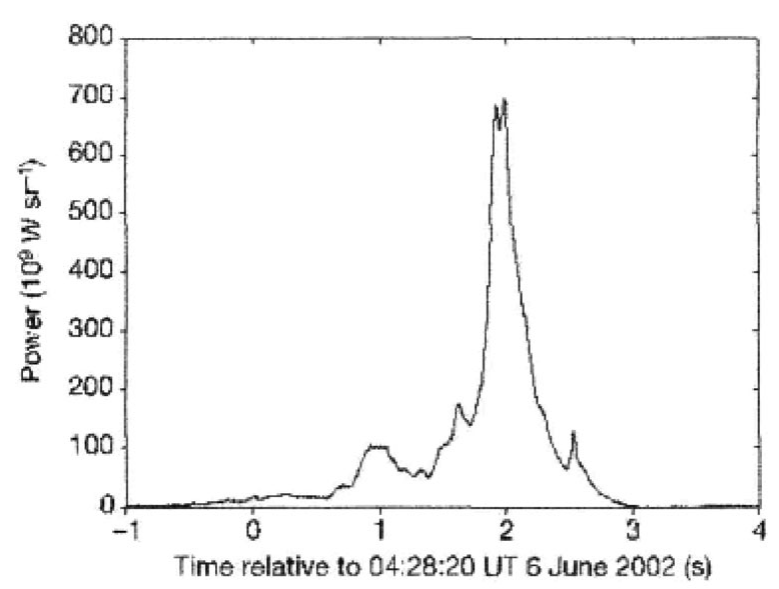

Figure 1. Optical curve of the bolide above the Mediterranean Sea, on 6 June 2002. 


\section{References}

Brown, P., Spalding, R. E., ReVelle, D. O. et al. 2002, Nature, 420, 314

Kruchynenko, V. G. 2004, Kinematics and physics of celest. bodies., 20(3), 269

McCrosky, R. E., Shao, C.- Y., \& Posen, A. 1976, Center for Astrophysics. Prep. Ser., 665, 13

McCrosky, R. E., Shao, C.- Y., \& Posen, A. 1977, Center for Astrophysics. Prep. Ser., 721, 61 